A 11 102 436168

NATL INST OF STANDAROS \& TECH R.I.C.

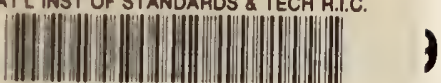

A11102436168

Pitis. William M/Chemically reacting fur

OC 100. U56 NO.85-3299 V1986 C.2 NBS-PUB-

\title{
Chemically Reacting Turbulent Flow
}

Reference

NBS

PUBLICATIONS

William M. Pitts.

Takashi Kashiwagi

U.S. DEPARTMENT OF COMMERCE

National Bureau of Standards

National Engineering Laboratory

Center for Fire Research

Gaithersburg, MD 20899

March 1986

$-Q C$

100

art by:

.456

ce

85-3299 ientific Research

1986 

U.S. DEPARTMENT OF COMMERCE

National Bureau of Standards

National Engineering Laboratory

Center for Fire Research

Gaithersburg, MD 20899

March 1986

Sponsored in part by:

U.S. Air Force

Office of Scientific Research

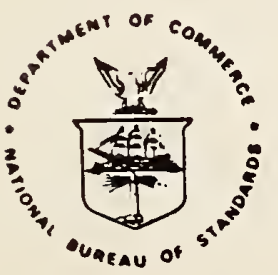

U.S. DEPARTMENT OF COMMERCE, Malcolm Baldrige, Secretary NATIONAL BUREAu OF STANDARDS. Ernest Ambler, Director 



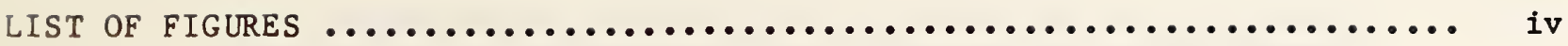

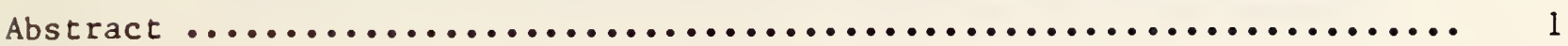

1. овJECTIVES ......................................... 2

2. STATUS OF RESEARCH $\ldots \ldots \ldots \ldots \ldots \ldots \ldots \ldots \ldots \ldots \ldots \ldots \ldots \ldots \ldots \ldots \ldots \ldots \ldots \ldots \ldots \ldots$

2.1 Introduction $\ldots \ldots \ldots \ldots \ldots \ldots \ldots \ldots \ldots \ldots \ldots \ldots \ldots \ldots \ldots \ldots \ldots \ldots \ldots \ldots \ldots \ldots$

2.2 Major Accomplishments and Findings ..................... 4

2.2.1 Development of Laser-Induced Rayleigh Light

Scattering as a Concentration Probe ................ 5

2.2.2 Development of a Technique for Simultaneous

Concentration and Velocity Measurement .............. 6

2.2.3 Development of a Digital Line Camera for

Concentration Measurements ....................... 8

2.2.4 Response Behavior of Hot-Wires and Films to Flows

of Different Gases ............................. 14

2.2.5 Effects of Global Density and Reynolds Number

Variations on Turbulent Mixing Behavior............... 15

2.2 .6 Final Remarks ................................ 20

3. PUBLICATIONS FOR FY83, FY84, AND FY85 ....................... 20

4. PROFESSIONAL PERSONNEL ................................ 21

5. INTERACTIONS FOR FY83, FY84, AND FY85 ...................... 21 


\section{LIST OF FIGURES}

$\underline{\text { Page }}$

Figure 1. Examples of simultaneous, time-resolved measurements of concentration and velocity for a turbulent jet of propane flowing into air are shown $\ldots \ldots \ldots \ldots \ldots \ldots \ldots \ldots \ldots \ldots \ldots$

Figure 2. The line camera system designed for line measurement of concentration is shown

Figure 3. The entire experimental system for making line measurements in the turbulent flow field of an axisymmetric jet is shown

Figure 4. An example of the results of time-resolved line measurements in a propane/air jet/coflow is shown. A seven level gray scale represents propane concentration having a maximum

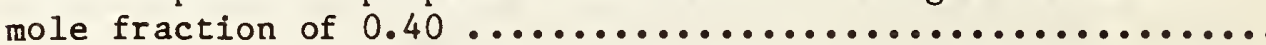

Figure 5. Correlation of Nusselt number as a function of Reynolds number for heat transfer from a hot-wire to nine different

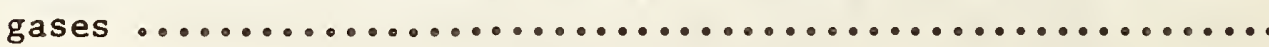

Figure 6. The experimental system for time-resolved shadowgraph imaging of variable density flows is shown schematically. Note that the coflowing gas is passed through the enclosure surrounding the nozzle .....................

Figure 7. A superposition of three shadowgraphs for an axisymmetric, turbulent jet of helium at $\operatorname{Re}=3950$ flowing into a slow

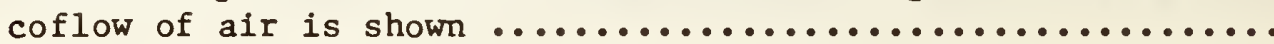

Figure 8. A superposition of four shadowgraphs for an axisymmetric, turbulent jet of propane at $\operatorname{Re}=3960$ flowing into a slow

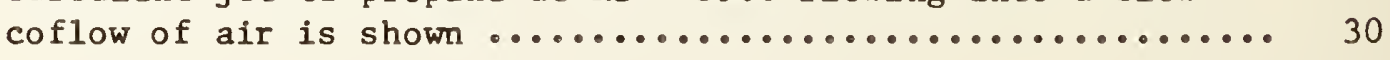

Figure 9. A shadowgraph is reproduced of an $\mathrm{SF}_{6}$ jet flowing into air which clearly shows the formation of a fountain by this

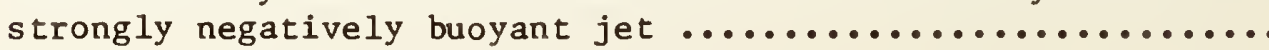

Figure 10. Centerline values of $\mathrm{Y}_{0} / \overline{\mathrm{Y}}_{\mathrm{T}}$ are plotted as functions of $\mathrm{z} / \mathrm{r}_{0}$ for the six different gas $/$ coflow combinations listed ........

Figure 11. Experimental values of $\mathrm{Y}_{0} / \overline{\mathrm{Y}}_{\mathrm{m}}$ are plotted as a function of $\left(z-z_{0}\right) / r_{\varepsilon}$ for the six different jet/coflow combinations

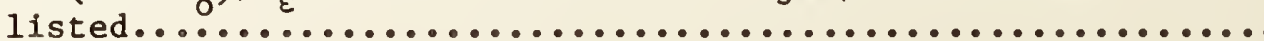

Figure 12. Centerline unmixedness values for six different jet/coflow combinations are plotted as functions of $z / r_{0} \ldots \ldots \ldots \ldots . .$.

Figure 13. The experimental results of figure 12 for $\mathrm{Y}_{\mathrm{m}}^{\prime} / \overline{\mathrm{Y}}_{\mathrm{m}}$ are

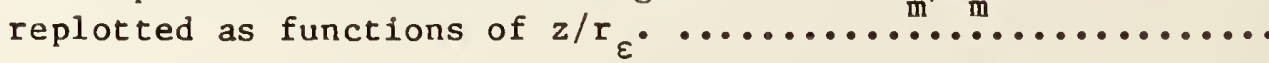


Figure 14. Unmixedness values are plotted as functions of $z / r_{0}$ for propane/air turbulent jets at three different Reynolds

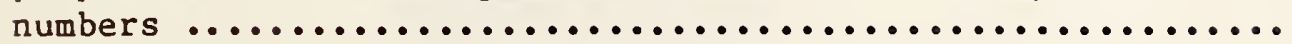





\section{CHEMICALLY REACTING TURBULENT FLOW}

William M. Pitts

Takashi Kashiwagi

Abstract

This report summarizes the results of the first three years of a study on chemically reacting turbulent flow. This project has been jointly sponsored by the Air Force Office of Scientific Research and the National Bureau of Standards. The development of new diagnostics for variable density flows are described. These include Rayleigh light scattering for real-time, spatiallyresolved concentration measurements, combined Rayleigh light scattering and hot-wire anemometry for simultaneous concentration and velocity measurements, and the development of a digital line camera which has allowed the concentration measurements to be made along a line. A study of heat transfer from heated cylinders is discussed which has generated a much improved correlation of experimental results. Shadowgraph visualization studies and centerline concentration measurements are described for variable density, axisymmetric turbulent jets covering jet to coflow density ratios of 0.14 to 37 . These studies have also included a limited investigation of Reynolds number effects. The observed dependence of the mixing behavior on the density ratio and $\operatorname{Re}$ have led us to make new hypotheses concerning the nature of turbulent mixing. These hypotheses are shown to lead to qualitative predictions for the turbulent mixing which are in agreement with experimental findings. 


\section{OBJECTIVES}

The primary objective of this research program has been and remains the improvement of the fundamental understanding of chemically reacting turbulent flow. Despite intense efforts for several decades, this complicated mixing process remains poorly characterized. This is unfortunate, since chemically reacting turbulent flows are of paramount importance in a wide range of combustion devices and other chemical reactors which have military and industrial uses. An improved understanding of the interactions of fluid dynamics and heat release is not only necessary to improve device efficiencies and contribute to the conservation of dwindling fuels and feed-stocks, but also to allow designs which limit the production and release of undesirable pollutants.

In order to meet the above objective, an approach has been adopted which seeks to first generate detalled experimental information concerning the effects on turbulent mixing of global density variations based on chemical composition or temperature. Once these effects are fully characterized, the study is to be extended to reacting flows where local fluctuations of density occur due to the heat release of chemical reactions. It is our conviction that it is first necessary to quantify the effects of global density differences before it is possible to understand the more complicated effects of local heat release. The experimental results which are described in this report not only serve to improve the qualitative understanding of mixing in variable density flows, but are also to be used for comparison with workers who are striving to develop quantitative models of these complex flows. 
An important secondary goal has been the development of new experimental techniques having high spatial and temporal resolution for the investigation of concentration and velocity in variable density flows. These diagnostics are required in order to gain insights into the temporal behavior of turbulent mixing processes.

\section{STATUS OF THE RESEARCH}

\subsection{Introduction}

This report summarizes findings for the initial three-year period of a study of chemically reacting turbulent flow which has been jointly sponsored by the Air Force office of Scientific Research (AFOSR) under contract numbers ISSA-83-00012, ISSA-84-00005, and ISSA-00012 and the National Bureau of Standards (NBS). Initially, this project was intended to be an integrated theoretical and experimental effort. To this end; Dr. Howard Baum of the Center for Fire Research was included as a principal investigator. However, during the course of the project, all of the parties involved agreed that it was best for the theoretical efforts of $\mathrm{Dr}$. Baum to be supported by AFOSR as an independent project. During the past year this change has been initiated and for this reason, the results to be summarized here are primarily exper1mental in nature. An active collaboration still exists between Dr. Baum and his coworkers and the principle investigators for this project.

Detailed descriptions of research findings during the first two years of this study are available in two previous annual reports, three project renewal requests, and several archival publications. Only short summaries of this 
work will be included here. Major emphasis will be placed on the research accomplishments during the past year.

\subsection{Major Accomplishments and Findings}

The following is a list of major accomplishments and findings which have been made during the three year period covered by this report. Short descriptions of each item follow. Recent results on the development of the line camera and the effects of global density variations on turbulent mixing behavior will be emphasized.

\section{Diagnostic Development}

i) Development of laser-induced Rayleigh light scattering as a real-time concentration probe in turbulent binary gas mixtures.

- Combination of laser-induced Rayleigh light scattering and hot-wire anemometry to allow real-time, simultaneous measurements of concentration and velocity in binary gas mixtures.

- Design and fabrication of a digital line camera capable of making real-time concentration measurements along a line located within a turbulent binary gas mixture. 
- Completion of a study of heat transfer from cylinders to a wide variety of gases. Results have led to the development of a new correlation procedure which incorporates the effects of molecular property variations with temperature.

- Completion of an investigation of global density effects on turbulent mixing in axisymetric jets. Density ratios for jet to surrounding gases cover the unprecedented range from 0.14 to 37 . Shadowgraph flow visualization and quantitative centerline concentration Deasurements have provided unique insights into the effects of global density variations on turbulent mixing as well as a new interpretation of the turbulent mixing process.

2.2.1. Development of Laser-Induced Rayleigh Light Scattering as a Concentration Probe

This work was initiated prior to the period covered by this report and completed during the early phases of the three-year study. Laser-induced Rayleigh light scattering was shown to be an extrenely useful method for performing real-time, spatially-resolved measurements in the flow fields of binary gas mixtures. Such measurements had been very difficult to make in the past. Measurement rates as high as $5 \mathrm{kHz}$ for observation volumes as swall as $0.0003 \mathrm{~m}^{3}$ were easily obtained. A maximum of 32,768 measurements could be recorded and stored as a continuous data record. 
Procedures were developed which allowed the average, rms, skewness, and kurtosis values to be calculated for the time-resolved concentration measurements. The availability of real-time data allowed the generation of intermittency functions which could be subsequently employed to provide conditionallysampled values of the concentration fluctuation moments. The time-resolved concentration records were used to generate both correlation functions and power spectra for the concentration fluctuations in the turbulent flow fields.

The technique was demonstrated by performing a series of concentration measurements for a turbulent jet of methane flowing into a slow coflow of air. The results were consistent with previous measurements available in the 1iterature. Even though of a preliminary nature, these measurements were recently chosen as the most reliable available for comparison purposes with the results of conserved scalar measurements in a hydrogen-air diffusion flame ("Superlayer Contributions to Conserved Scaler PDF's in a $\mathrm{H}_{2}$ Turbulent Jet Diffusion Flame", M.C. Drake, W. Shyy, and R.W. Pitz, Fifth Symposium on Turbulent Shear Flows, Ithaca, New York, August 7-9, 1985).

2.2.2. Development of a Technique for Simultaneous Concentration and Velocity Measurement

There are very few velocity measurement techniques available for variable density flows. Hot-wire anemometry is complicated by the variations in fluid heat transfer behavior which occur in turbulent gas mixtures. By combining the laser-induced Rayleigh method with hot-wire anemometry it was possible to correct the observed hot-wire response for variations in the molecular properties of the fluid surrounding the velocity probe and obtain accurate velocity measurements. Since both the light scattering and anemometer signals 
were digitally recorded, simultaneous time-resolved records of concentration and velocity were generated. These records allowed the cross-correlation coefficient for velocity and concentration fluctuations to be calculated. Such terms appear in many theoretical treatments of turbulent flow and their measurement is therefore of great interest.

A system was fabricated in which a hot-wire or hot-film was placed very near the observation volume for a laser-1nduced Rayleigh IIght scattering concentration measurement. By measuring the response of the probe to known velocities of different binary gas mixtures in the concentration range of interest, calibration curves were generated which allowed the flow velocity to be determined when the hot-wire or hot-film response and surrounding gas composition were avallable. In this way, the entire velocity time record was generated.

The effectiveness of this new measurement technique was demonstrated by making simultaneous, time-resolved measurements of concentration and velocity within an axisymmetric turbulent jet of propane flowing into air. The experimental results were shown to be in excellent agreement with the limited number of measurements which are avallable in the literature. Figure 1 shows an example of the simultaneous, time-resolved measurements of concentration and velocity which were recorded. 
2.2.3. Development of a Digital Line Camera for Concentration Measurements

The two techniques described above permit real-time measurements of concentration and velocity in variable density flows having an accuracy and ease which has only become possible very recently. Even so, it is clear that a great deal of information concerning the nature of the three-dimensional flow structures which form the turbulent field cannot be elucidated by point measurements.

In the past few years new optical techniques have been developed which allow both line (along a laser beam) and two-dimensional (sheet lighting) measurements of scalars in turbulent flow fields. Even though these techniques are in a relatively early stage of development, dramatic demonstrations of their ability to visualize scalar variations in turbulent flow fields have been published (e.g., see "Visualization of Turbulent Flame Fronts with Planar Laser-Induced Fluorescence", G. Kychakoff, R.D. Howe, R.K. Hanson, M.C. Drake, R.W. Pitz, M. Lapp, and C.M. Penney, Science 224 (1984) 382).

These new flow diagnostics have been made possible by the recent development of suitable area detectors. In general, the optical processes which are utilized are too weak to be recorded directly by these detectors and some means of image intensification has been required to generate the necessary light levels. Pulsed laser sources are usually employed. These provide excellent time resolution, but are incapable of real-time measurements in turbulent flows due to their low repetition rates. 
It became clear to us very early that the extension of these new optical imaging techniques to real-time Rayleigh light scattering measurements provided a unique opportunity for investigating mixing in variable density flows. In FY84, NBS provided supplemental funding which allowed the design and fabrication of a line camera designed especially for making such measurements. During the past fiscal year this camera has been constructed and its usefulness demonstrated by recording real-time concentration fluctuations along a line located within the flow field of a turbulent jet of propane flowing into air.

The design of this camera presented severe technological challenges in the areas of image intensification, solid-state array detection, and data acquisition. Each of the components chosen for the camera in its current configuration are described briefly below.

The utilization of a solid-state detector capable of operating at $\mathrm{kHz}$ or higher rates requires that the laser-induced Rayleigh light scattering intensity be increased in some way. Most past measurements have utilized generation II image intensifier tubes for this purpose. These devices were originally developed for night vision use. They provide extremely high light amplification (values of $10^{5}$ are not uncommon), but their maximum brightness is limited by current saturation which occurs in the microchannel plates which serve as the active gain media in this type of tube. Calculations showed that generation II image intensifiers could not provide enough brightness to allow light intensity measurements at $\mathrm{kHz}$ rates with commercially-available, solidstate detectors. 
Fortunately, similar calculations indicated that an earlier type of image intensifier (designated generation I) could operate at higher internal current levels and hence generate brighter outputs than generation II tubes. These earlier devices function by accelerating and electrostatically focusing electrons generated by a photocathode which subsequently strike a phosphor. Their light gains are lower than generation II tubes, but the light amplification required for the application described here is relatively modest and the ability to generate brighter outputs is the primary consideration. On this basis, a generation I image Intensifler tube was chosen to amplify the light generated by Rayleigh light scattering.

In choosing an output phosphor for the image intensifier it was necessary that the decay time be sufficiently short to insure that the tube could respond to the temporal fluctuations of the input light source. The most common phosphor utilized in these devices is P-20. This particular phosphor decays relatively slowly and its lifetime is long enough to limit the time resolution of an image intensifier operating in the $\mathrm{kHz}$ range. For this reason, the image intensifier used in the camera to be described here was equipped with a P-47 output phosphor. This blue phosphor has a submicrosecond lifetime which is sufficiently short to insure that the tube responds fully to input 1 ight intensity fluctuations on a $\mathrm{kHz}$ time scale.

There are a wide range of solid-state photodetectors commerclally available. Important considerations in choosing a particular array include pixel size, read rate, and single read capability. For this study, a linear 
s111con photodiode array produced by Reticon (RLI28S) was chosen.* Tnis array consists of 128 individual pixels located on $0.025 \mathrm{~mm}$ centers which have heights of $2.5 \mathrm{~mm}$. The active length is therefore $3.2 \mathrm{~mm}$. Reticon provides standard electronics which are used to drive the array and produce a sampled and held video signal which is a voltage output proportional to the intensity of light on a given pixel during the integration time for the read. Pixel read times can be varied with rates approaching a MH/pixel possible. By operating at these high rates, the entire array can be scanned in less than 1 ms.

The detector array and image intensifier are both equipped with fiber optic faceplates. These allow the two devices to be coupled with a $4: 1$ reduction fiber optic taper. This taper not only serves to isolate the line scanner from the high voltage of the image intensifier tube, but also allows a 12.8 line image on the intensifier to be imaged onto the 3.2 mactive length of the detector array. This reduces the effective resolution of the system to 0.150 which is comparable with that available in past single point concentration measurements utilizing photomultipliers.

The camera system was completed by incorporating a $1: 1$ lens which forms an image of the Rayleigh scattering on the input face of the 1mage intensifier. A schematic of the camera and the placement of the varfous components is shown in figure 2. The insert shows that the small end of the fiber optlc taper has been coated with aluminum and then scribed across its center with a

\footnotetext{
*Certain commercial equipment, instruments, or materials are identified in this paper in order to adequately specify the experimental procedure. Such identification does not imply recomendation or endorsement by the National Bureau of Standards, nor does it imply the waterials or equipment are necessarlly the best available for the purpose.
} 
$0.200 \mathrm{~mm}$ wide line. This arrangement serves to limit light reaching the detector to only the $0.200 \mathrm{~mm}$ wide region defined by the scribed portion.

In order to make quantitative measurements of scattering intensity it is necessary to record digitally the sampled and held output of the line camera. This requires that the camera be interfaced to a data acquisition system which is capable of digitizing and storing data at rates near a MHz. A Nicolet 1180 signal averaging computer was used. Figure 3 shows the system which was formed by interfacing the line camera to the Nicolet. The minimum digitization time is $3 \mu \mathrm{s}$. This limits the scan rate for the entire array to a maximum value of $2.2 \mathrm{kHz}$. The available memory is 32,768 words which means that only 256 array scans can be stored before the data must be transferred to a hard disk.

As a demonstration of the camera system, the time-resolved Rayleigh light scattering along a laser beam within the turbulent flow region of an axisymmetric jet of propane into air was recorded. Figure 3 shows that the Ar ion laser beam and the digital line camera are oriented at $90^{\circ}$ to one another. The configuration of the jet and the slow coflow of surrounding air are also indicated in this drawing.

By calibrating the scattering from pure air and propane it was possible to obtain quantitative measurements of spatially-and temporally-resolved propane concentration in the flow field. Figure 4 shows the results for measurements recorded along a $12.8 \mathrm{~mm}$ line located 31.5 jet radif from the jet orifice and lying along the jet radius from roughly 2 to 6 nozzle radil. In this figure, the radial location is given simply by the pixel number. This 
reflects the fact that the data have not been corrected for small variations In 1mage intensifier magnification with position. The readout time for the array was $1.9 \mathrm{~ms}$. The time scale for the measurements and the flow direction are indicated on the vertical axes. Propane concentration is represented by a seven level gray scale where the maximum mole fraction is approximately 0.40 .

Some nolse is evident in the measurements. This is due to a slight electronic plckup by the linear detector from the image intensifier. In the future, this nolse will be suppressed by improvements in the hardware or by digital correction. Despite the noise, the turbulent fluctuations of propane mole fraction are clearly evident. The results show dramatically the importance of large scale structures in turbulent mixing. Data such as that shown in fig. 4 can be time-averaged in exactly the same manner as the point measurements described earlier. In this way, it has been shown that concentration measurements utilizing the line camera are in quantitative agreement with earlier polnt measurements in the same flow.

In its current configuration the sensitivity of the line camera is such that only the favorable case of a propane jet into air can be investigated at $\mathrm{kHz}$ data rates. In order to extend these measurements to other gas pairs, it is necessary to increase the light sensitivity of the camera. An analysis of the optical efficiencies of the various components of the camera has been completed. Design modifications are now being generated which should significantly improve the camera sensitivity and allow a wide range of gas palrs to be investigated at high data rates. 
2.2.4. Response Behavior of Hot-Wires and Films to Flows of Different Gases

During our efforts to develop hot-wire anemometry as a velocity probe in variable density flows it became apparent that the heat transfer laws available in the literature were not sufficient to predict the heat loss behavior of a heated cylinder in different pure gases, much less mixtures of two or more gases. Since such a correlation for heat transfer would greatly simplify the tedious calibrations required in order to utilize the hot-wire technique in variable density flows, a study of the responses of hot-wires and films to varying flow velocities of different gases was carried out. Responses were experimentally determined for flows of ten gases (alr, $\mathrm{N}_{2}, \mathrm{He}, \mathrm{CH}_{4}, \mathrm{C}_{3} \mathrm{H}_{8}, \mathrm{CO}_{2}$, $\mathrm{Ar}, \mathrm{CF}_{4}, \mathrm{CF}_{3} \mathrm{Br}$, and $\mathrm{SF}_{6}$ ) having a wide range of molecular weights and properties. Mixtures of these gases were also studied.

Data of this type are generally correlated by plotting the nondimensionalized variables of Nusselt number $(\mathrm{Nu})$ as a function of the Reynolds number ( $R e$ ) based on the cylinder diameter. In order to improve the correlation of the results for pure gases, corrections were applied to the data for heat losses by conduction at the probe ends, Knudsen number effects due to the small size of the probes, and the lack of total thermal "accommodation" of the available energy by gas molecules striking the heated surface of the probe. Even after these corrections, it was necessary to consider variations in molecular properties with temperature among the different gases. This last correction allowed the experimental results to be correlated to within the accuracy to which the molecular properties are known. Figure 5 shows the resulting correlation. $\left(K_{B}\right)_{x}$ and $\left(K_{A}\right)_{X}$ are parameters which account for the variations in molecular properties among the different 
gases and are given explicitly as $\left(k_{B}\right)_{x}=\left[\left(\nu_{m} / \nu_{\infty}\right)_{x} /\left(\nu_{m} / \nu_{\infty}\right)_{a i r}\right]^{1.355}$ and $\left(K_{A}\right)_{x}=\left(A_{C}\right)_{a i r}-\left[\left(\mu_{m}\right)_{a i r} /\left(\mu_{m}\right)_{x}\right]^{0.222}\left(A_{c}\right)_{a i r}$ for gas $x$. The subscripts $m$ and $\infty$ refer to dynamic $(\mu)$ or kinematic $(\nu)$ viscosities evaluated at the average of the probe surface and ambient temperatures or ambient temperatures, respectively.

The correlation shown in fig. 5 is a significant improvement over others avallable in the 11terature. This result demonstrates the importance of utilizing a number of gases having wide variations in molecular weights and properties when investigating heat transfer processes.

When the results of calibrations in mixtures of gases were considered, systematic differences were found between the data and the correlations determined using the procedure for pure gases. We attribute these variations to the importance of thermal diffusion to heat transfer in gas mixtures. This conclusion is still a subject of active experimental and theoretical effort in our group.

2.2.5. Effects of Global Density and Reynolds Number Variations on Turbulent Mixing Behavior

During the first two years of this project an extensive serles of measurements of centerline concentration behavior were made for He/alr, $\mathrm{CH}_{4}$ /air, $\mathrm{C}_{3} \mathrm{H}_{8} / \mathrm{CO}_{2}, \mathrm{C}_{3} \mathrm{H}_{8} / \mathrm{air}, \mathrm{SF}_{6} / \mathrm{air}$, and $\mathrm{SF}_{6} / \mathrm{He}$ jet/coflow gas pair combinations. Most measurements were made with $\operatorname{Re} \approx 4000$ (based on tube diameter), but measurements for the $\mathrm{C}_{3} \mathrm{H}_{8}$ /air and $\mathrm{SF}_{6}$ /air cases were extended to higher $\mathrm{Re}$ In order to elucidate the importance of Re on the mixing behaviors of the jets. Coflow velocities were low enough to insure that the confined jets could be well approximated as free jets. 
In FY85 a simple pulsed shadowgraph system was developed which allowed these variable density flows to be visualized. Figure 6 shows the schematic for the experimental system and figs. 7-9 show examples of the shadowgraphs which were observed. The He/air and $\mathrm{C}_{3} \mathrm{H}_{8} /$ air flows shown in figs. 7 and 8 , respectively, were both recorded at the same $\mathrm{Re}$. The different appearances of the two shadowgraphs are qualitative indications of global density effects on turbulent mixing behavior (see ahead). Figure 9 shows the downstream region of a $\mathrm{SF}_{6}$ /air flow at relatively low Re. This jet is extremely negatively buoyant, and, as the shadowgraph clearly shows, forms a fountain at relatively short downstream distances.

The centerline concentration measurements were extended during the past year to include $\mathrm{CF}_{4}$ jets at $\operatorname{Re}$ of 3960 and 7920 flowing into slow coflows of air. Quantitative data are now available for seven different gas pairs covering a jet/coflow density range of 0.14 to 37 . This is the most extensive density range ever investigated in a single flow system. If these density variations were due to temperature differences referenced to room temperature, the range would be 8 to $2100 \mathrm{~K}$. This wide range has allowed us to identify several effects of global density differences which have not been previously reported. These results along with those for the Re effects study led us to generate new hypotheses concerning the development and mixing behavior of turbulent flows (see ahead). Experimental results have also been compared with the predictions of several different similarity analyses.

Due to space limitations, the experimental results, analyses, and conclusions will only be briefly discussed here. A full manuscript has been prepared and is undergoing NBS internal review. It should be available soon 
as an NBS internal report and will also be submitted to an archival journal for publication.

Figure 10 shows the centerline concentration behaviors for six different gas pairs plotted as $\mathrm{Y}_{\mathrm{O}} / \overline{\mathrm{Y}}_{\mathrm{m}}$ versus the nondimensionalized downstream distance, $z / r_{0}$. Y represents the time-averaged mass fraction of jet gas and the subscripts $o$ and $m$ refer to values at the nozzle exit and along the jet centerline, respectively. Clearly, the rate at which the average centerline concentration decreases is dependent on the density ratio of the jet to surrounding gases. Straight lines represent linear least squares curve fits of the data and show that the virtual origins ( $\mathrm{z}$ value where $\mathrm{Y}_{\mathrm{o}} / \overline{\mathrm{Y}}_{\mathrm{m}}$ passes through zero) also vary systematically with the density ratio.

Approximate similarity analyses available in the literature have indicated that data for these variable density flows should fall on straight Iines having identical slopes when plotted versus $z / r_{\varepsilon}$, where $r_{\varepsilon}$, the effective radius, is equal to $r_{0}\left(\rho_{0} / \rho_{\infty}\right)^{1 / 2}$. $\rho_{0}$ and $\rho_{\infty}$ are the densities of the jet and surrounding gases. This expression is based on conservation of momentum arguments.

Figure 11 shows the experimental data of fig. 10 plotted as a function of $\left(z-z_{0}\right) / r_{\varepsilon}$, where $z_{0}$ are the virtual origins for the different sets of data. It is clear that the effective radius concept does give an improved correlation of experimental results. Systematic variations with density ratio remain and are attributed to a breakdown in the similarity conditions at the near field positions for which the measurements have been made. 
RMS values of the centerline concentration, $Y_{m}^{\prime}$, normalized by the local average concentration are shown plotted as a function of $z / r_{0}$ in $f 1 g \cdot 12$. $\mathrm{Y}_{\mathrm{m}}^{\prime} / \bar{Y}_{\mathrm{m}}$ values are often referred to as concentration intensities or unmixedness. Figure 12 shows that the unmixedness values for the various jets seem to approach a common asymptote of $\left(\mathrm{Y}_{\mathrm{m}}^{\prime} / \overline{\mathrm{Y}}_{\mathrm{m}}\right)$ asym $\approx 0.23$, but that the downstream distance required for a given flow to attain this value depends strongly on the density ratio. Negatively buoyant jets require longer distances than positively buoyant flows.

To our knowledge, this is the first observation of such density effects on the centerline growth of unmixedness in turbulent axisymmetric jets. A remarkable collapse of the unmixedness values occurs when the results are plotted as functions of $\mathrm{z} / \mathrm{r} \varepsilon^{\circ}$ Figure 13 shows the results. This is dramatic evidence that the correct turbulence axial length scale for these flows is indeed $r_{\varepsilon}$ and not $r_{0} \cdot$

A very curious $\operatorname{Re}$ number dependence has been observed in this study. Plots of $Y_{0} / \bar{Y}_{m}$ versus $z / r_{0}$ are found to have slopes which are independent of and virtual origins which are displaced downstream as the Re is increased. On the other hand, as fig. 14 shows, the approach of centerline unmixedness to its asymptotic value is slowed dramatically at higher Re. This finding is in conflict with the generally accepted view that higher Re are required in order to observe fully-developed turbulent behavior.

On the basis of the qualitative differences observed in the shadowgraphs and the quantitative centerline concentration measurements, two hypotheses have been formulated which lead to qualitative predictions for turbulent flow 
behavior which agree with the experimental observations. These hypotheses are:

1. The time-averaged mixing behavior as well as values of unmixedness are determined primarily by large scale structures; and

2. A finite time and downstream distance are required for the entire length scale structure of the turbulent flow to come into a pseudoequilibrium. The downstream distance required increases as the turbulent eddy structure extends to smaller scales.

These assumptions lead to predictions of the variations observed in centerline values of average concentration and unmixedness for jets having different jet to coflow density ratios. All that is required is that the large scale structures in the turbulent eddy size distribution scale as $r_{\varepsilon}$ instead of $r_{0}$ in the axial direction. Evidence that this is indeed the case can be seen in the shadowgraphs for the different jets where the visualized structures of the jets having higher jet to coflow density ratios appear to be elongated along the axial direction (compare figs. 7 and 8 ). These arguments suggest that variations in the centerline development of jet fluid unmixedness with $\operatorname{Re}$ are due to the wider range of eddy sizes which are present in the higher Re flows with the result that longer downstream distances are required for the eddies to come into a pseudoequilibrium. Note that these hypotheses might well explain variations in unmixedness development which have been widely discussed in the literature. 
The ideas discussed above must be considered as speculative at the present time. However, they do provide a framework for understanding the results of the current study. Further work is clearly required to test, validate, and quantify the predictions.

\subsubsection{Final Remarks}

During the initial three years of this project significant progress has been made on the development of new diagnostics for variable density flow fields as well as the generation of the data necessary to characterize and ultimately predict the effects of global density variations on turbulent mixing. It is expected that these techniques and the resulting measurements will contribute significantly to the overall goal of this work - namely, Improving the fundamental understanding of chemically reacting turbulent flow.

\section{PUBLICATIONS FOR FY83, FY84, AND FY85}

1. "The Application of Laser-Induced Rayleigh Light Scattering to the Study of Turbulent Mixing", W.M. Pitts and T. Kashiwagi, National Bureau of Standards Internal Report (NBSIR 83-2641), January 1983.

2. "The Application of Laser-Induced Rayleigh Light Scattering to the Study of Turbulent Mixing", W.M. Pitts and T. Kashiwagi, J. Fluid Mech. 141 (1984) $391-429$.

3. "A New Diagnostic for Simultaneous, Time-Resolved Measurement of Concentration and Velocity in Simple Turbulent Flow Systems", W.M. Pitts, B.J. McCaffrey, and T. Kashiwagi, Proceedings of the Fourth Symposium on Turbulent Shear Flows, Karlsruhe, West Germany, September 12-14, 1983.

4. "Response Behavior of Hot-Wires and Films to Flows of Different Gases", W.M. Pitts and B.J. McCaffrey, National Bureau of Standards Internal Report (NBSIR 85-3203), July 1985.

5. "Response Behavior of Hot-Wires and Films to Flows of Different Gases", W.M. Pitts and B.J. McCaffrey, submitted to J. Fluid Mech. (1985). 
6. "Effects of Global Density and Reynolds Number Variations on Mixing in Turbulent, Axisymnetric Jeets", W.M. Pitts, to be published as National Bureau of Standards Internal Report (1985).

7. "Effects of Global Density and Reynolds Number Variations on Mixing in Turbulent, Axisymmetric Jets", W.M. Pitts, to be submitted to J. Fluid Mech. (1985).

\section{PROFESS IONAL PERSONNEL}

In addition to the principle investigators, Dr. Bernard McCaffrey of the Center for Fire Research has worked on the anemometry calibrations in different gases.

5. INTERACTIONS FOR FY83, FY84, AND FY85

1. "Concentration Measurements in Simple Turbulent Flow Systems Using Rayleigh Light Scattering", W.M. Pitts and T. Kashiwagi, presented by W.M. Pitts at the 1982 Fall Meeting of the Western States Section of the Combustion Institute, Livermore, CA, October 11-12, 1982.

2. "Chemically Reacting Turbulent Flow", W.M. Pitts, T. Kashiwagi, and H.R. Baum, presented by W.M. Pitts at the 1982 AFOSR Contractors Meeting on Airbreathing Combustion Dynamics Research, Clearwater Beach, FL, November $1-4,1982$.

3. "A New Diagnostic Technique for Simultaneous, Time-Resolved Measurement of Concentration and Velocity in Simple Turbulent Flow System", W.M. Pitts, B.J. McCaffrey and T. Kashiwagi, presented by W.M. Pitts at the 1982 Fal1 Technical Meeting of the Eastern States Section of the Combustion Institute, Atlantic City, NJ, December 14-16, 1982.

4. "A New Diagnostic Technique for Simultaneous, Time-Resolved Measurement of Concentration and Velocity in Simple Turbulent Flow Systems", W.M. Pitts, B.J. McCaffrey, and T. Kashiwagi, presented by W.M. Pitts at the Fourth Symposium on Turbulent Shear Flows, Karlsruhe, West Germany, September 12-14, 1983.

5. "Chemically Reacting Turbulent Flow", W.M. Pitts, T. Kashiwagi, and H.R. Baum, presented by T. Kashiwagi at the 1983 AFOSR Contractors/Grantees Meeting on Airbreathing Combustion Dynamics Research, Scottsdale, AR, September 19-23, 1983. 
6. "The Application of Laser-Induced Rayleigh Light Scattering to the Study of Turbulent Mixing", presented by W.M. Pitts to the Nuclear Engineering Seminar of the Department of Chemical and Nuclear Engineering, University of Maryland, College Park, MD, October 30, 1984.

7. "Response Behavior of Hot-Wires and Films in Different Gases", W.M. Pitts and B.J. McCaffrey, presented by W.M. Pitts at the 37 th Annual Meeting of the American Physical Society, Division of Fluid Mechanics, Providence, RI, November 18-20, 1984.

8. "Chemically Reacting Turbulent Flow", W.M. Pitts and T. Kashiwagi, presented by W.M. Pitts at the AFOSR/ONR Contractors Meeting in Combustion, Pasadena, CA, July 23-25, 1985.

9. "Development of an Intensified Digital Line Camera System for Rea1-Time Line Measurements in Turbulent Flows", presented by W.M. Pitts at the 1985 Fall Technical Meeting of the Eastern Section of the Combustion Institute, Philadelphia, PA, November 4-6, 1985. 
Figure 1. Examples of simultaneous, time-resolved measurements of concentration and velocity for a turbulent jet of propane flowing into air are shown.
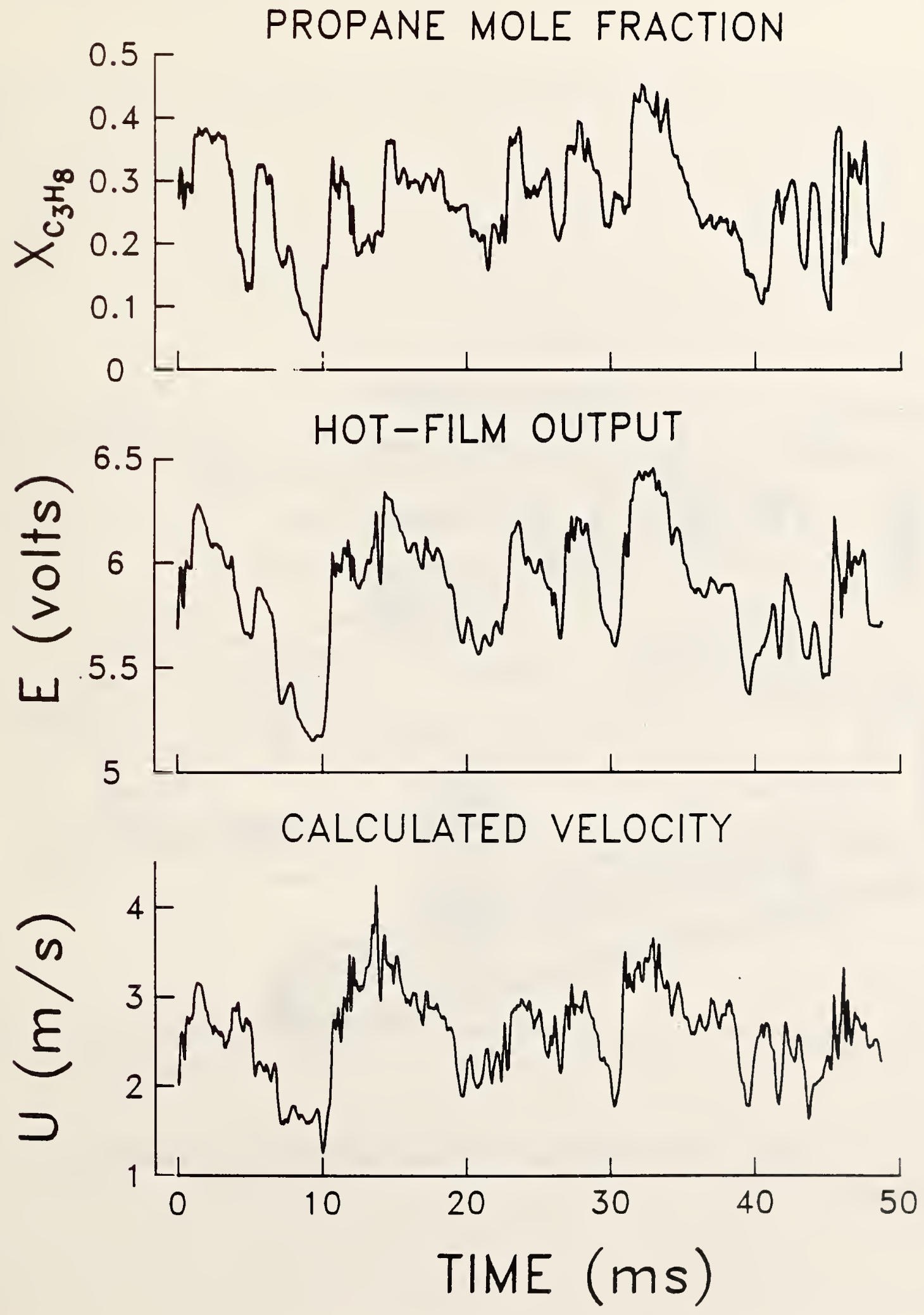


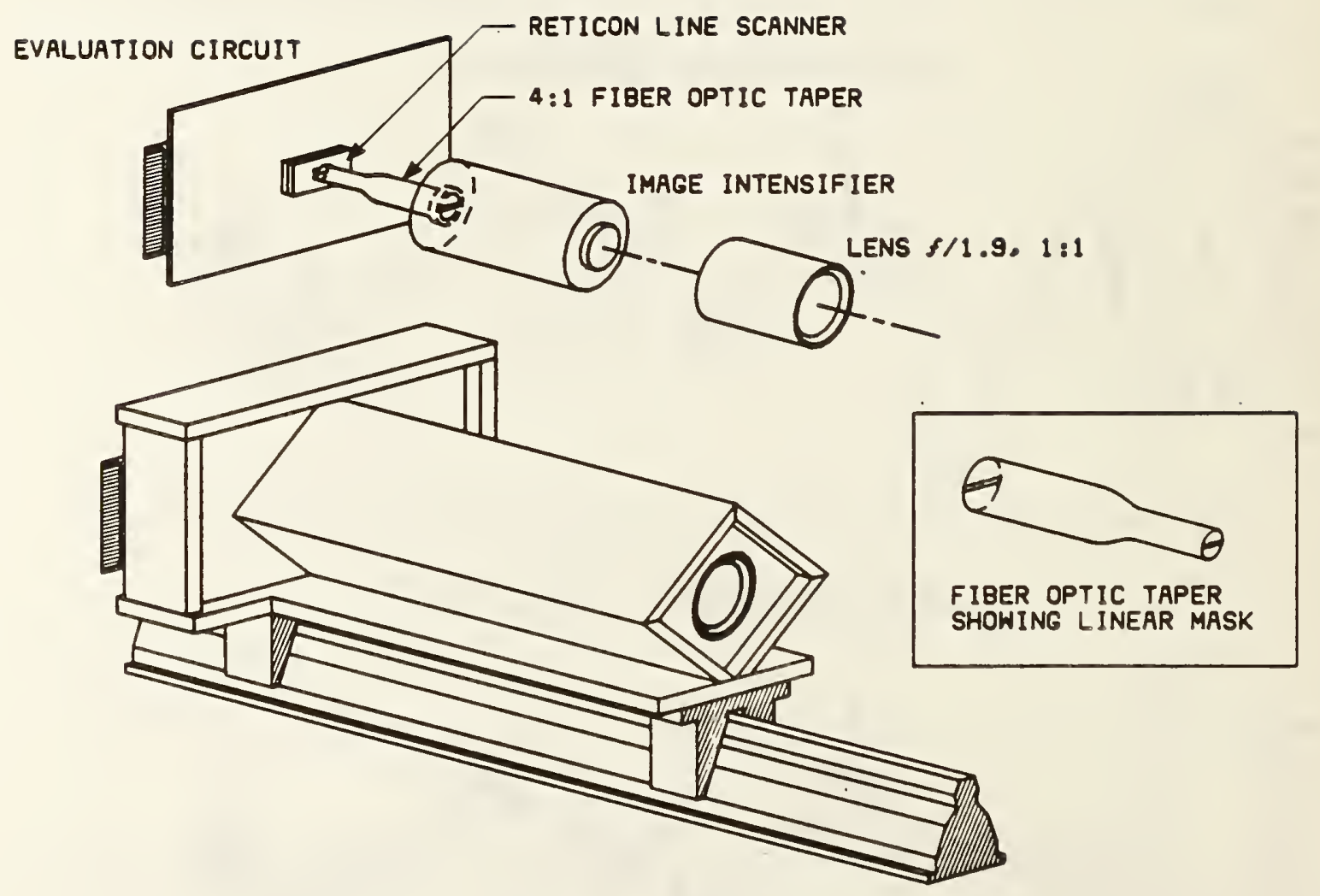

Figure 2. The line camera system designed for line measurement of concentration is shown. 


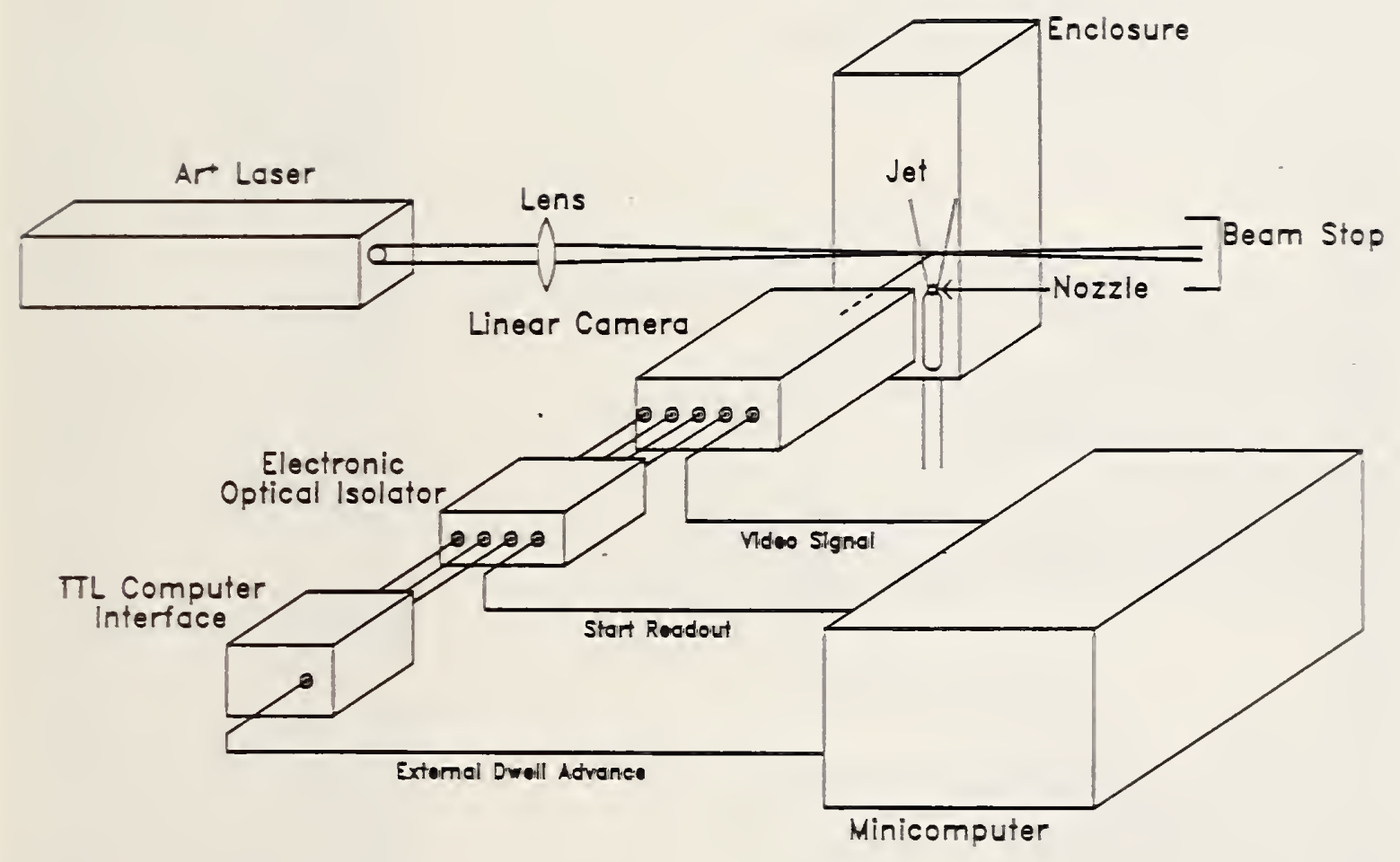

Figure 3. The entire experimental system for making line measurements in the turbulent flow field of an axisymetric jet is shown. 

Figure 4. An example of the results of time-resolved line measurements in a propane/air jet/coflow is shown. A seven level gray scale represents propane concentration having a maximum mole fraction of 0.40 .

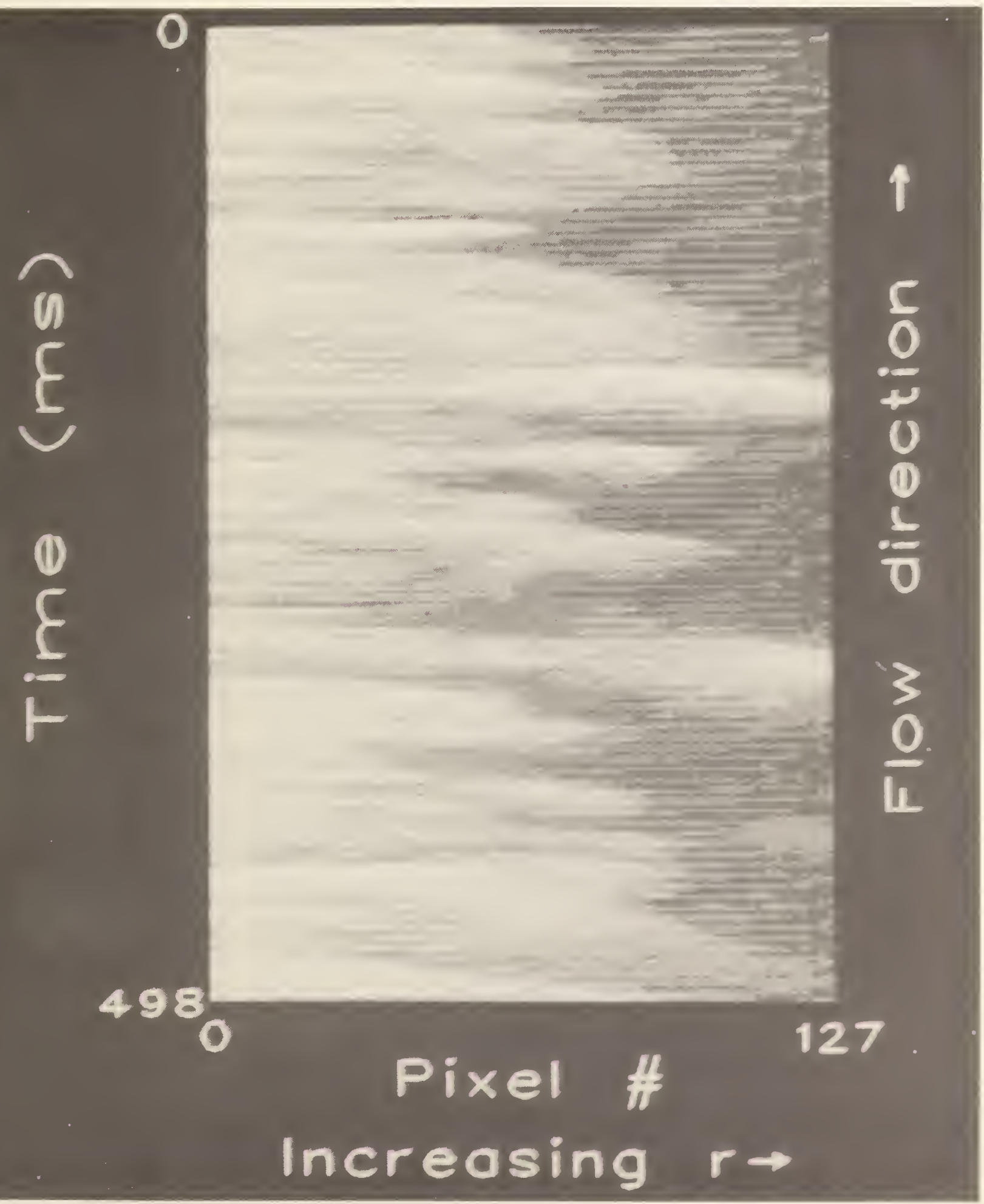





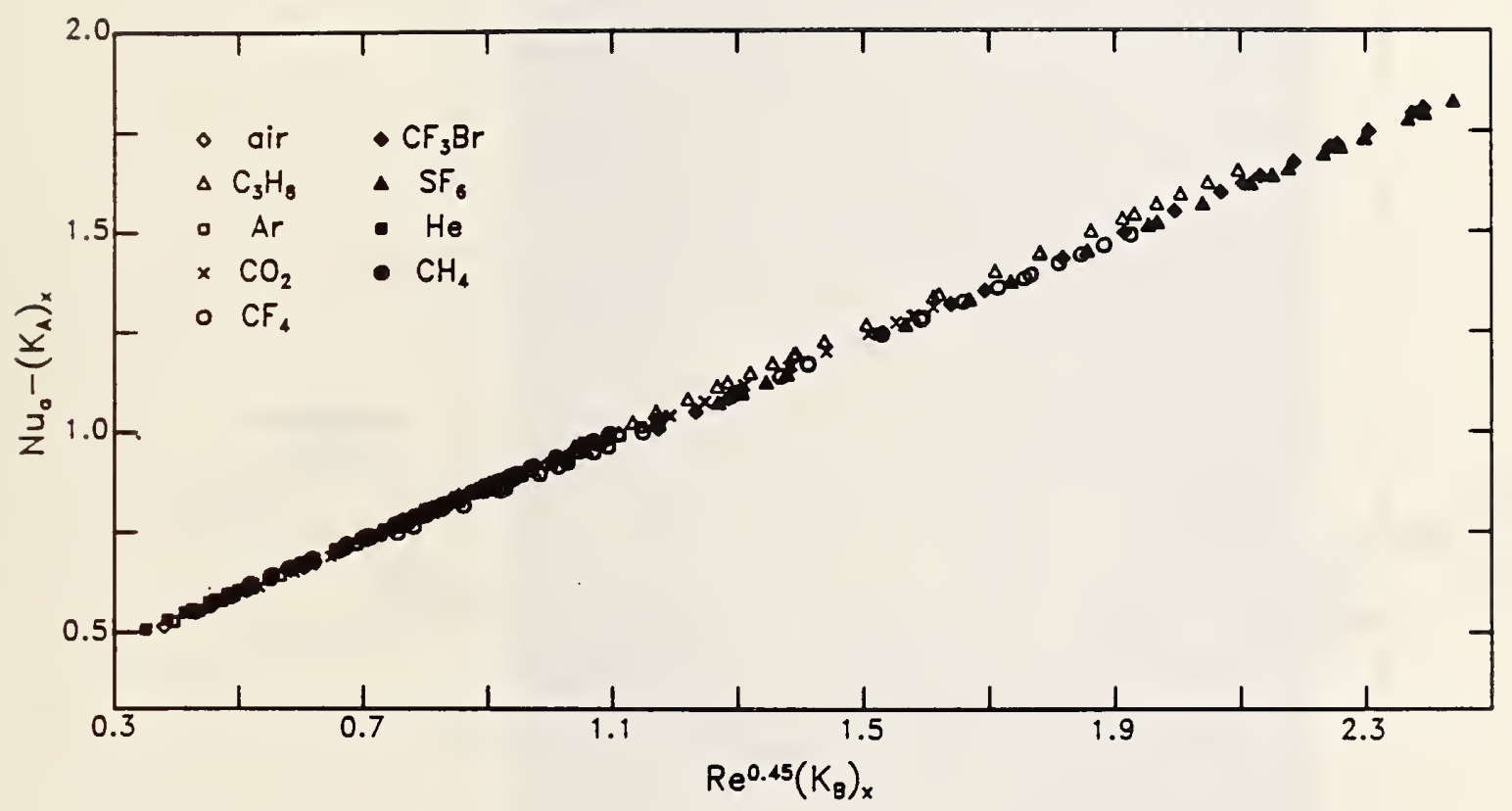

Figure 5. Correlation of Nusselt number as a function of Reynolds number for heat transfer from a hot-wire to nine different gases. 


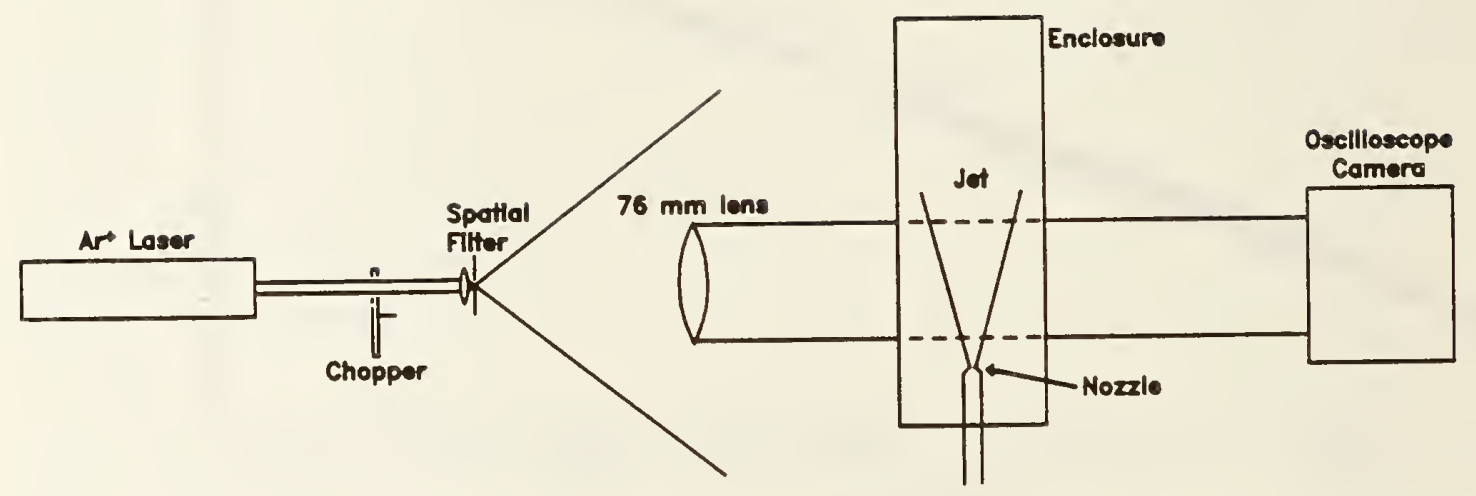

Figure 6. The experimental system for time-resolved shadowgraph imaging of variable density flows is shown schematically. Note that the coflowing gas is passed through the enclosure surrounding the nozzle. 
Figure 7. A superposition of three shadowgraphs for an axisymmetric, turbulent jet of helium at $\operatorname{Re}=3950$ flowing into a slow coflow of air is shown.

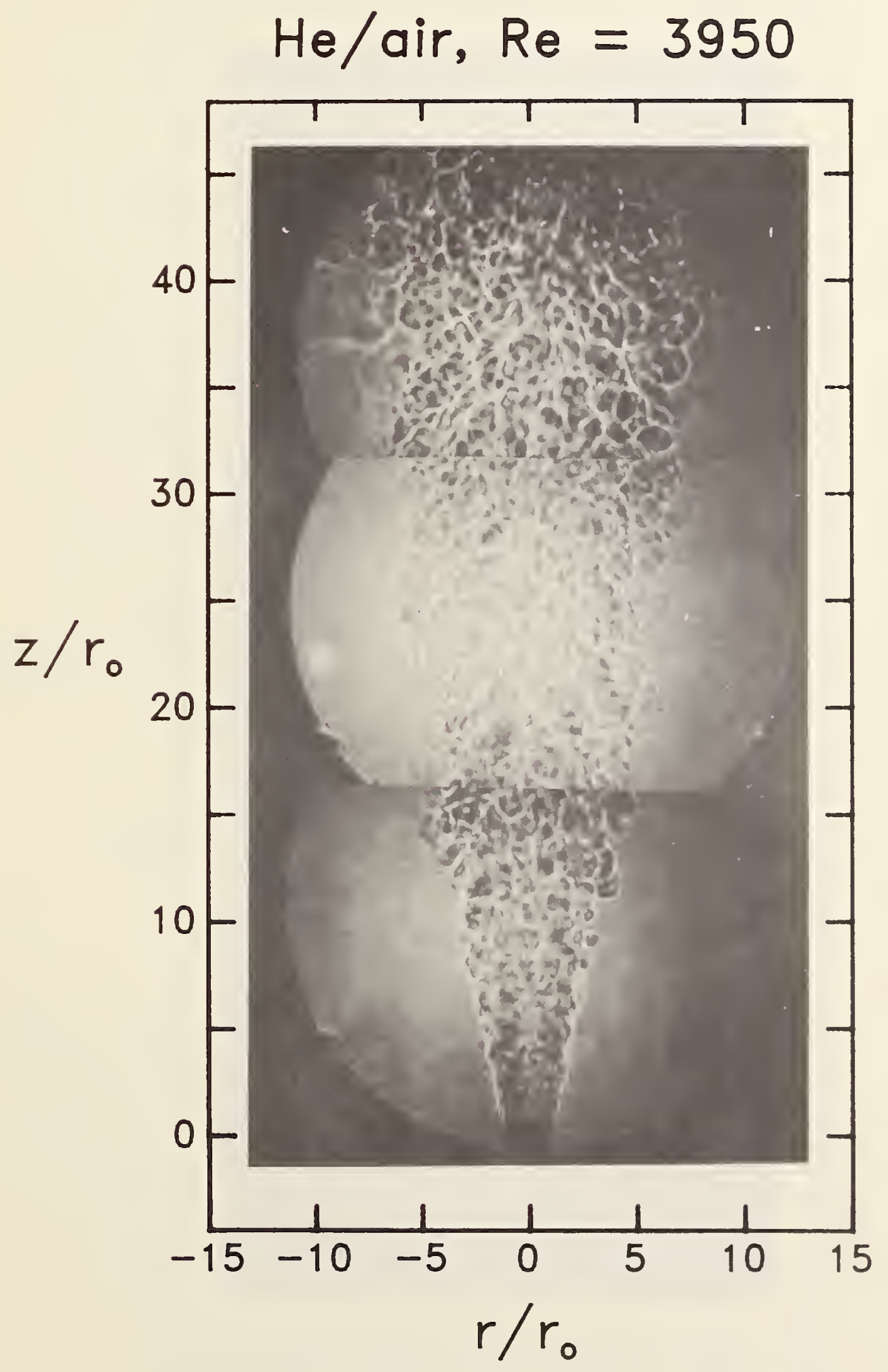



Figure 8. A superposition of four shadowgraphs for an axisymmetric, turbulent jet of propane at $\mathrm{Re}=3960$ flowing into a slow coflow of air is shown.

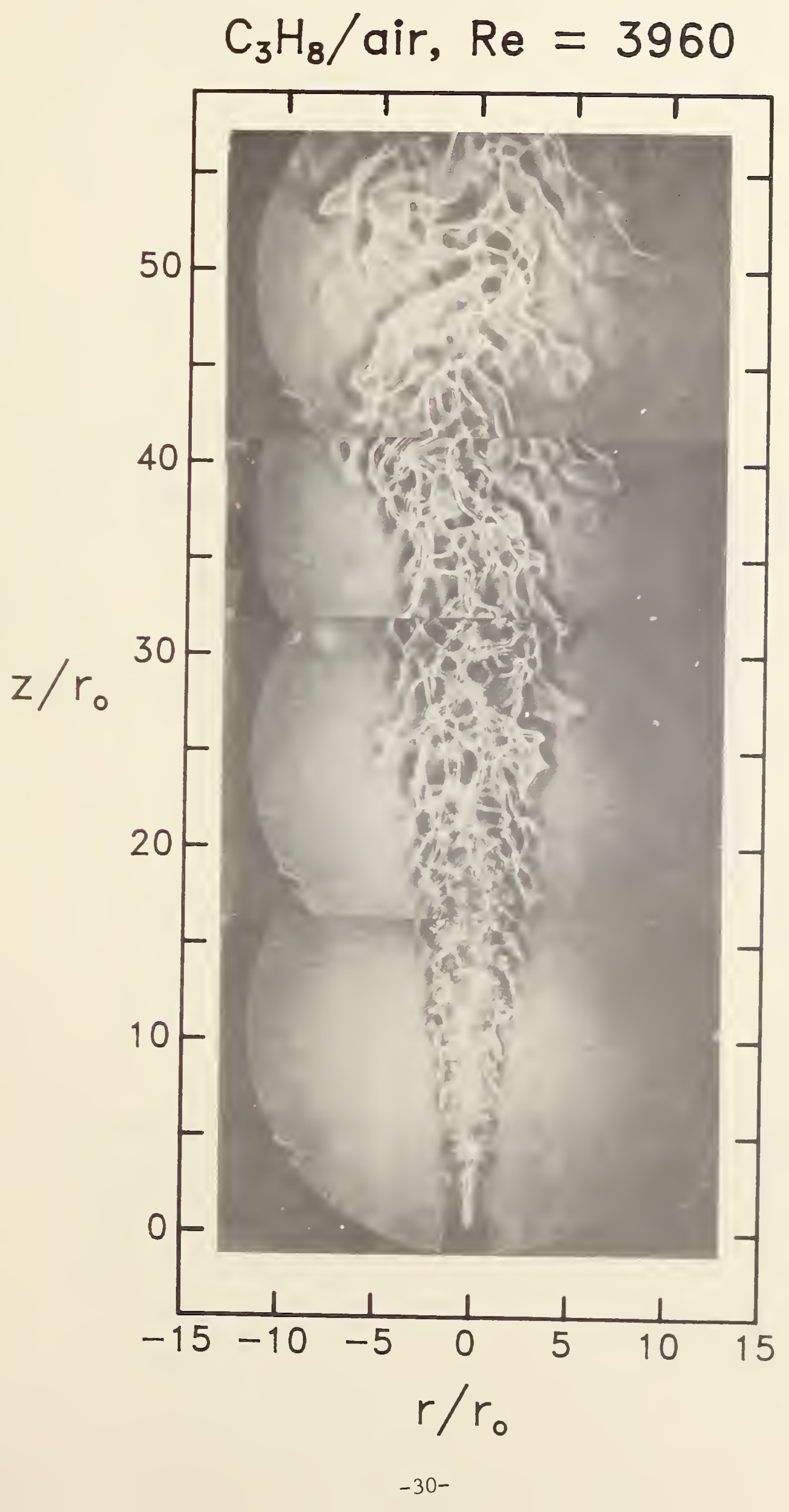





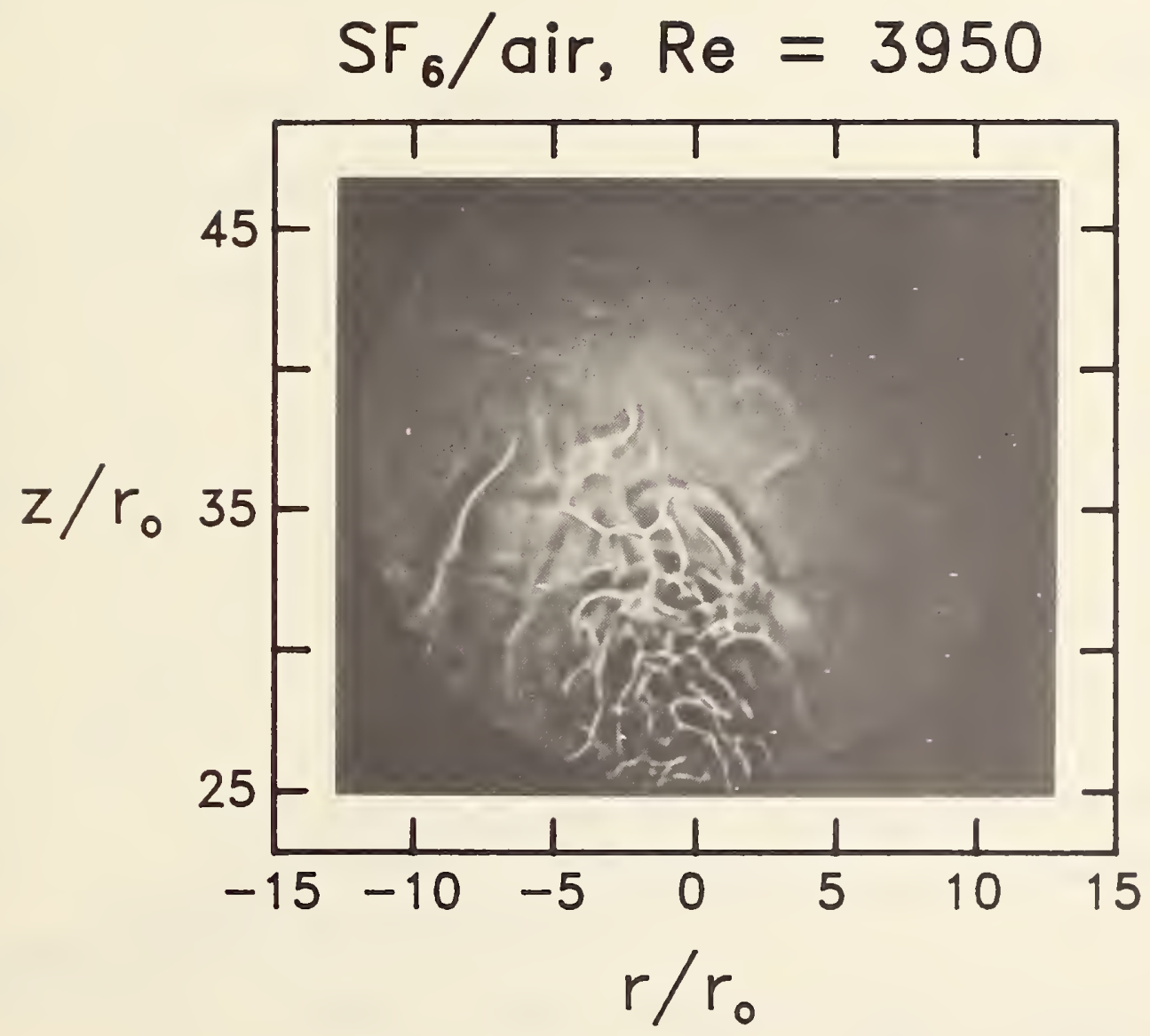

Figure 9. A shadowgraph is reproduced of an $\mathrm{SF}_{6}$ jet flowing into air which clearly shows the formation of a fountain by this strongly negatively buoyant jet. 



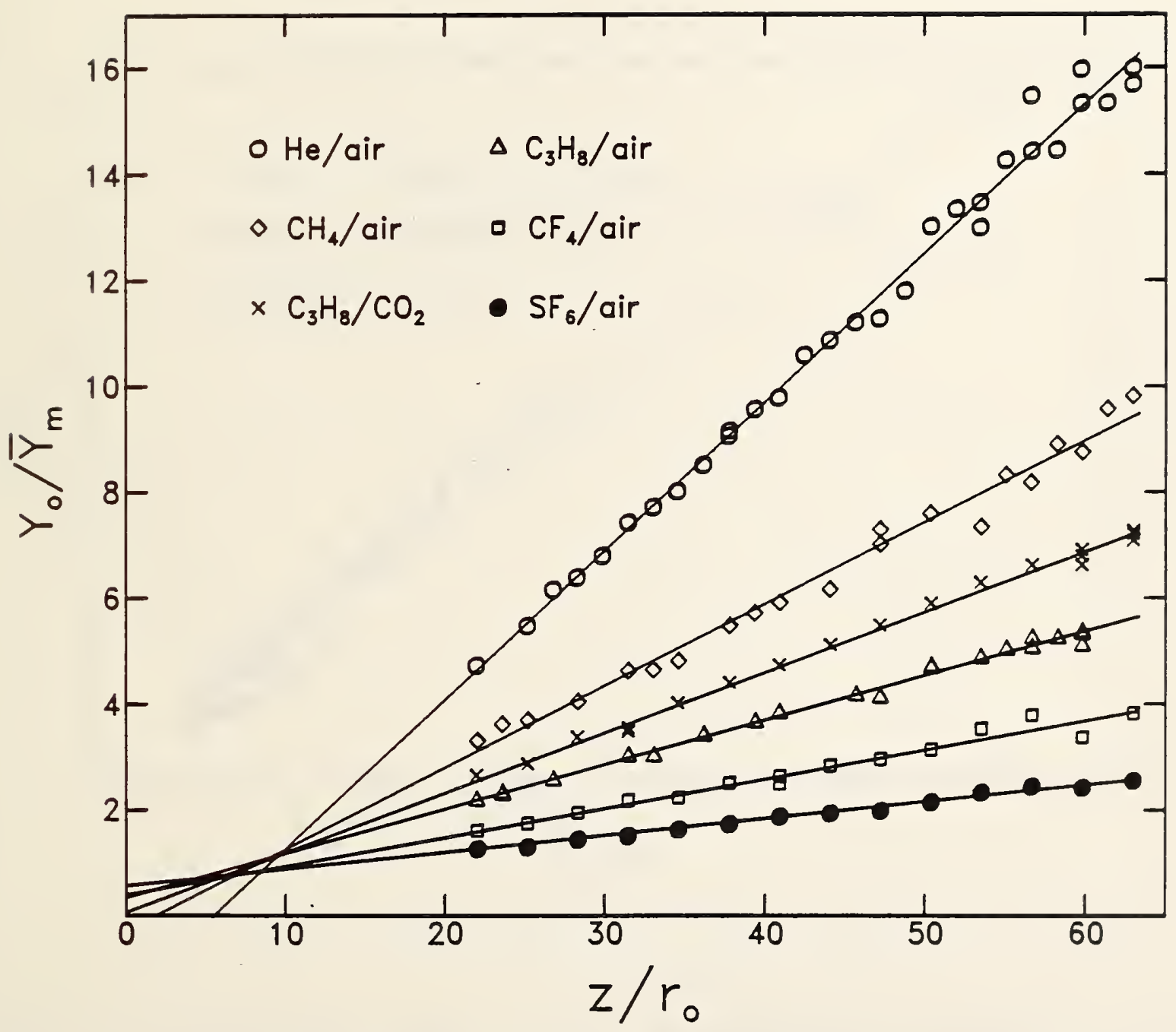

Figure 10. Centerline values of $\mathrm{Y}_{\mathrm{o}} / \overline{\mathrm{Y}}_{\mathrm{m}}$ are plotted as functions of $\mathrm{z} / \mathrm{r}_{\mathrm{o}}$ for the six different gas/coflow combinations listed. 



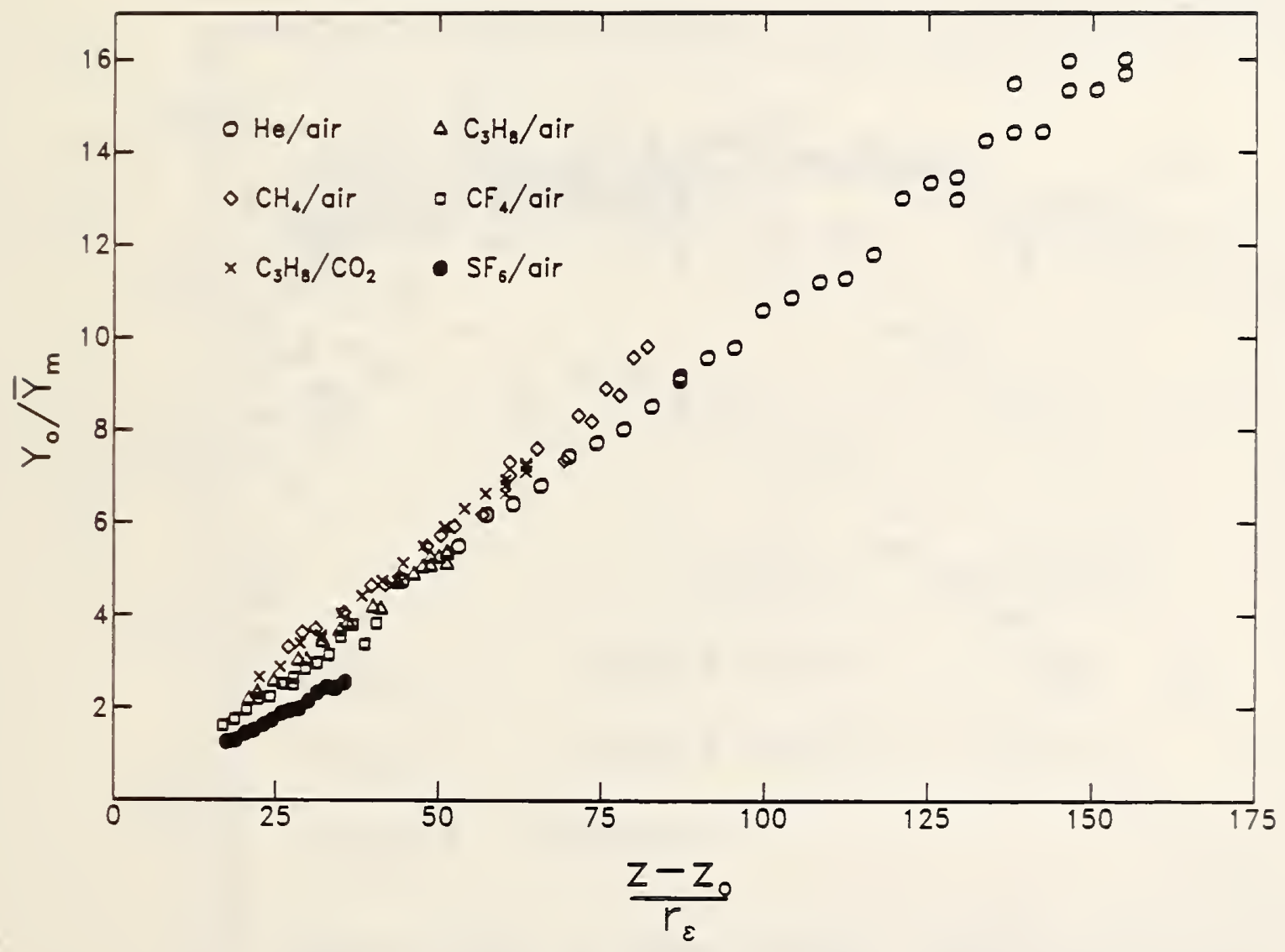

Figure 11. Experimental values of $\mathrm{Y}_{0} / \bar{Y}_{\mathrm{m}}$ are plotted as a function of $\left(z-z_{0}\right) / \tau_{\varepsilon}$ for the six different jet/coflow combinations listed. 


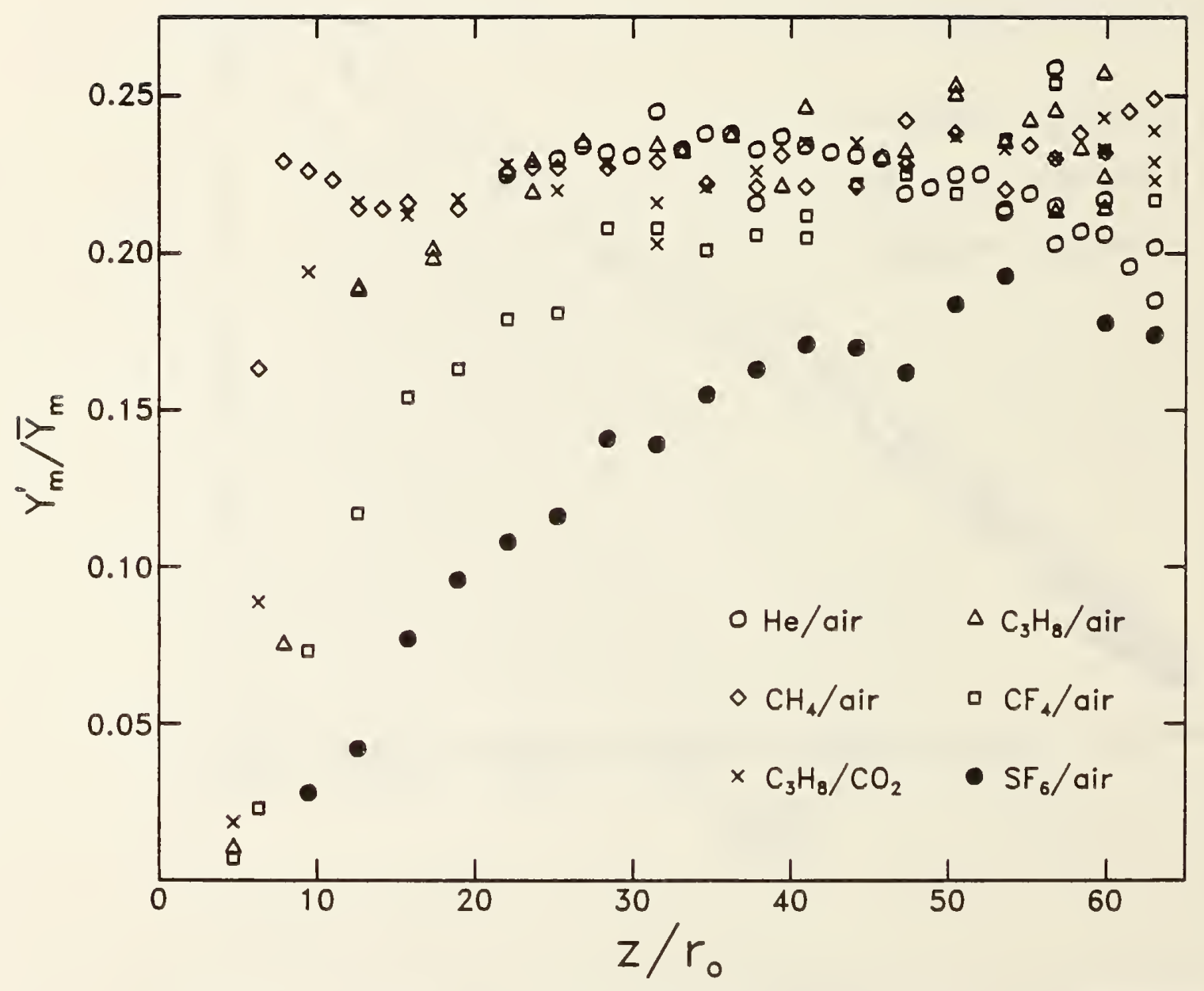

Figure 12. Centerline unmixedness values for six different jet/coflow combinations are plotted as functions of $z / r_{0}$. 


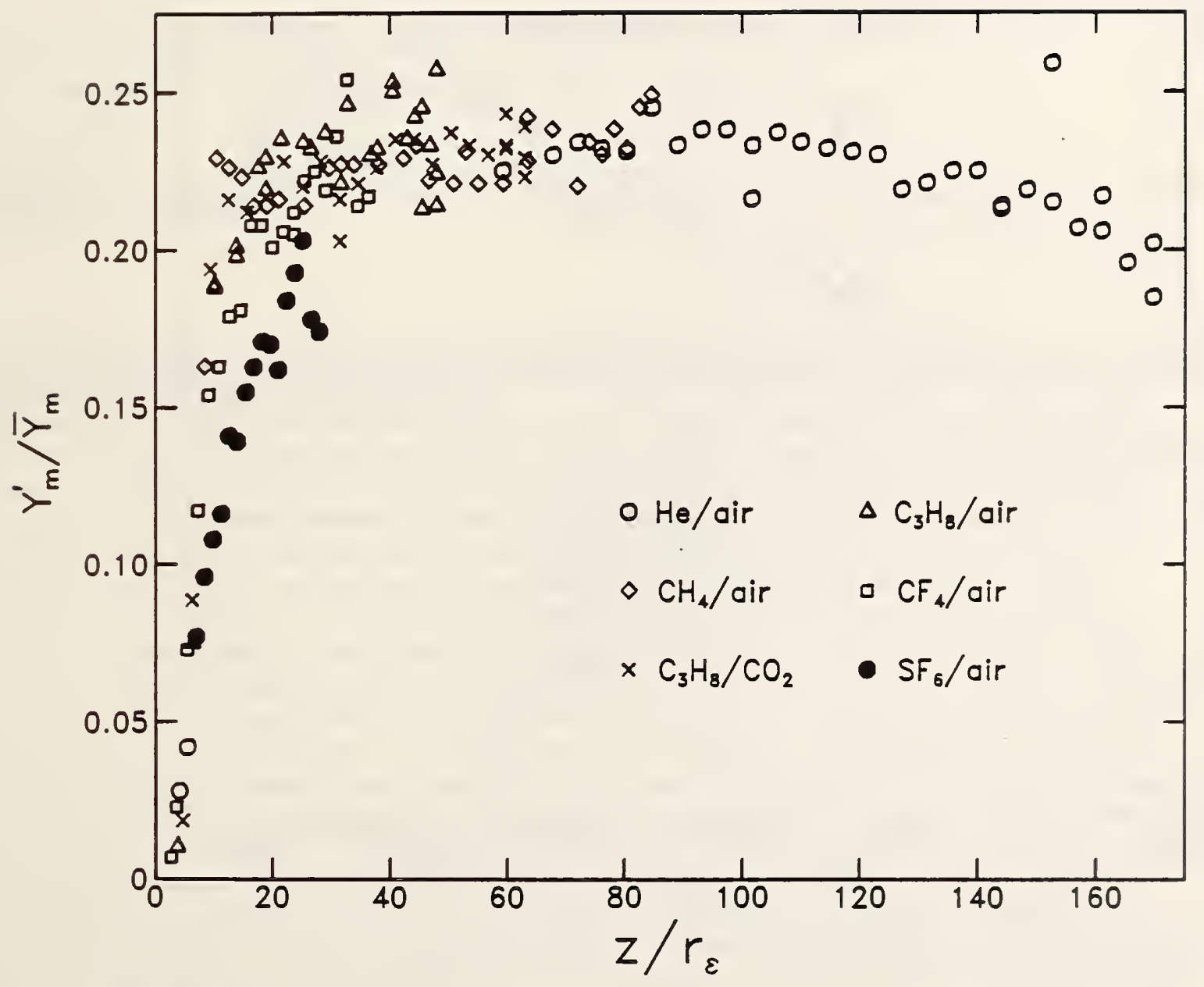

Figure 13. The experimental results of figure 12 for $Y_{m}^{\prime} / \bar{Y}_{m}$ are replotted as functions of $z_{i} r_{\varepsilon}$. 


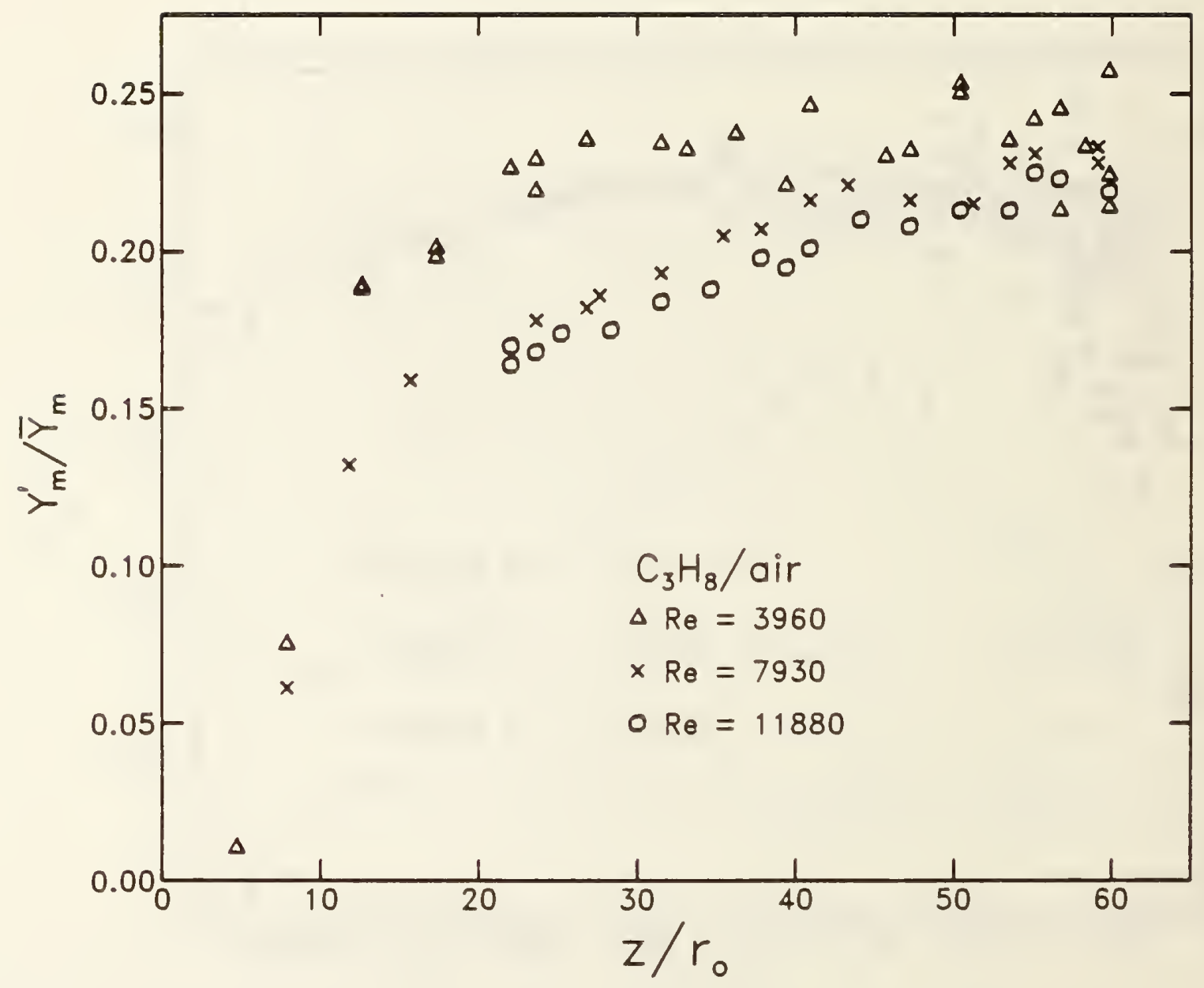

Figure 14. Unmixedness values are plotted as functions of $z / r_{0}$ for propane/air turbulent jets at three different Reynolds numbers. 
1. TITLE AND SUBTITLE

Chemically Reacting Turbulent Flow. Annual Progres's Report for October 1, 1984 to September 30, 1985 and Final Technical Report for the Three Year Period from October 1, 1982 to September 30, 1985

\section{AUTHOR(S)}

Will1am M. Pitts, Takashi Kashiwagi

6. PERFORMING ORGANIZATION (If joint or other than NBS, see instructions)

MATIONAL BUREAU OF STANDARDS DEPARTMENT OF COMMERCE

Galthersburg, MD 20899

7. Contract Grant No.

$\triangle F O S R-T S S A-00012$

8. Type of Report \& Period Covered

Final 10/1/82-9/30/85

3. SPONSORING ORGANIZATION NAME AND COMPLETE ADCRESS (Street, City, Stote, ZIP)

Air Force Office of Scientific Research

Bolling AFB

Building 410

Vasbington, DC 20332

10. SUPPLEMENTARY NOTES

Document describes a computer program; SF-185, FIPS Software Summary, is attached.

11. ABSTRACT (A 200-word or less factual summary of most significant information. If document includes a significant bibliography or literature survey. mention it here)

This report summarizes the results of the first three years of a study on chemically reacting turbulent flow. This project has been jointly sponsored by the Air Force office of Scientific Research and the National Bureau of Standards. The development of new diagnostics for variable density flows are described. These include Rayleigh light scattering for real-time, spatially-resolved concentration measurements, combined Rayleigh light scattering and hot-wire anemometry for simultaneous concentration and velocity measurements, and the development of a digital line camera which has allowed the concentration measurements to be made along a Iine. A study of heat transfer from heated cylinders is discussed which has generated a much improved correlation of experimental results. Shadowgraph visualization studies and centerline concentration measurements are described for variable density, axisymmetric turbulent jets covering jet to coflow density ratios of 0.14 to 37 . These studies have also included a limited investigation of Reynolds number effects. The observed dependence of the mixing behavior on the density ratio and $\mathrm{Re}$ have led us to make new hypotheses concerning the nature of turbulent mixing. These hypotheses are shown to lead to qualitative predictions for the turbulent mixing which are in agreement with experimental findings.

12. KEY WORDS (Six to twelve entries; alphabetical order: capitalize only proper names; and separate key words by semicolons) Concentration fluctuations; concentration measurement; density effects; digital line camera; flow visualization; hot wire anemometry; Rayleigh light scattering: Reynolds number: velocity measurements 13. AVAILABILITY

조 Unlimited

$\square$ For Official Distribution. Do Not Release to NTIS

$\square$ Order From Superintendent of Documents, U.S. Government Printing Office, Washington. D.C. 20402.

14. NO. OF PRINTED PAGES

$8]$ Order From National Technical Information Service (NTIS), Springfield, VA. 2216I

\section{7}

15. Price 

.

$$
-
$$


